\title{
Parabiotic Effect on the Gerebral Lesions in the Spontaneously Hypertensive Rats
}

\author{
Akinobu Nagaoka, Hisashi Iwatsuka, Ziro SuzuokI, \\ and Kozo Oкамото
}

Incidences of the cerebral lesions, hemorrhage and/or softening, in several sublines of SHR are significantly higher in $A_{3}$ than in $\mathrm{C}$ (Okamoto et al: In Spontaneous Hypertension, Igaku Shoin, Tokyo, 129, 1972). However, the pathogenesis of the lesions is still unclear. In this study parabiotic experiment was performed on $\mathrm{A}_{3}$ and $\mathrm{C}$ to explore a participation of humoral factor(s) in the development of the cerebral lesions.

The SHR ( $\mathrm{A}_{3}$ and $\mathrm{C}$ ) of $\mathrm{F}_{29-30}$ generation and normal Wistar/Kyoto rats (WK) were used at 50 to 60 days of age. Parabiosis was made by the method modified by Yamori (Jap Circulat J $35: 821$, 1971) in the combinations of $A_{3}$ to $\mathrm{C}$ and $\mathrm{A}_{3}$ to WK. Animals were maintained on a standard laboratory chow and tap water. Some pairs of $\mathrm{A}_{3}-\mathrm{C}$ were given $1 \% \mathrm{NaCl}$ solution instead of tap water ad libitum from 10th day after the operation. Systolic blood pressure was measured before and every 1 or 2 weeks after the operation by a microphonic method under the unanesthetized condition.

Body weight and animal condition: All pairs of the SHR lost their body weight gradually during the first 2 weeks, and then they were restored from the injury. In the combination of $\mathrm{A}_{3}-\mathrm{WK}, 5$ of 6 pairs showed histoincompatibility 7 to 8 weeks after the operation.

Blood pressure: At the start of experiment the average blood pressure was 174 for $A_{3}$ and $168 \mathrm{mmHg}$ for $\mathrm{C}$. Blood pressure change in 14 pairs of $A_{3}-G$ could be classified into 3 patterns: (a) In 5 pairs of this combination, the systolic blood pressure of $\mathrm{A}_{3}$ rose rapidly to $260 \mathrm{mmHg}$ during the first 4 weeks which was much higher than that of nonparabiotic $A_{3}$, and in their partner $\mathrm{C}$ the pressure fell to $126 \mathrm{mmHg}$ which was much lower than that of non parabiotic $\mathrm{C}$. (b) In 7 pairs, either $\mathrm{A}_{3}$ or $\mathrm{G}$ showed a similar blood pressure to that of respective nonparabiotic animals. (c) In 2 pairs, the blood pressure rose in $\mathrm{C}$ to about $220 \mathrm{mmHg}$ and fell in $\mathrm{A}_{3}$ to about $140 \mathrm{mmHg}$ during the observation period.

When the blood pressure of $A_{3}$ was plotted to that of the partner $C$ in all pairs, there was a negative correlation between $\mathrm{A}_{3}$ and $\mathrm{C}(\mathrm{r}=0.934, \mathrm{P}<0.01$

From the Biological Research Laboratories, Central Research Division, Takeda Chemical Industries, Ltd, Osaka; and Department of Pathology, Faculty of Medicine, Kyoto University, Kyoto. 
at 5th week; $\mathrm{r}=0.830, \mathrm{P}<0.01$ at 7 th week). From this phenomenon, it may be postulated that the blood pressure reducing factor(s), increasing compensatively with the advance of hypertension, is transfered to partners with lower blood pressure. However, in pairs of $\mathrm{A}_{3}$-WK there was not such a correlation: the blood pressure of WK was not affected by parabiosis with $A_{3}$. The absence of the effect of SHR on Wistar rats was repeatedly confirmed by other investigators (Yamori : Jap Circulat J 35: 821, 1971; Ebihara: In Spontaneous Hypertension. Igaku Shoin, Tokyo, 214, 1972). In NaClloaded $A_{3}-C$ pairs, the blood pressure of $A_{3}$ rose more sharply than that of $\mathrm{A}_{3}$ in the same pairs administered tap water. But $\mathrm{NaCl}$-loading had no effect on the blood pressure of the partner $\mathrm{C}$, which quite differed from the case of nonparabiotic C.

Cerebral lesions: In 5 pairs (pattern a), all of $\mathrm{A}_{3}$ developed the cerebral lesions associated with severe hypertension. In 7 pairs (pattern $b$ ), only one $A_{3}$ showed the lesions although the blood pressure of $A_{3}$ was similar to that of nonparabiotic $A_{3}$. In these combinations there was no lesion in all of $\mathrm{C}$. The blood pressure in 2 pairs (pattern c) was higher in $C$ than in $A_{3}$, but the G-rats did not show any cerebral lesions until 20 weeks after the operation. When loaded $\mathrm{NaCl}$-solution, $10 \mathrm{~A}_{3}$ of 10 pairs of $\mathrm{A}_{3}-\mathrm{C}$ developed the cerebral lesions within 35 days after the loading, but the partner $\mathrm{C}$ did not show any changes in their brains.

These results suggest that it is not likely that humoral and transmissible factor(s) participate in the development of the cerebral lesions of the subline $\mathrm{A}_{3}$. 